\title{
Phonological Errors among Dyslexic and Non-Dyslexic Children Learning Persian
}

\author{
Shahram Jamali Nesari \\ Islamic Azad University, Eyvan-e-Gharb Branch, Ilam, Iran \\ E-mail: Shahramjamali50@yahoo.com \\ Elahe Kamari (Corresponding author) \\ Young Researchers and Elite Clube, Islamic Azad University, Eyvan-e-Gharb Branch, Ilam, Iran \\ E-mail: Elahe.kamari4@gmail.com
}

\begin{abstract}
Received: 02-10- 2014
Accepted: 29-12- 2014

Advance Access Published: January 2015

Published: 01-05- 2015

doi:10.7575/aiac.ijalel.v.4n.3p.167

URL: http://dx.doi.org/10.7575/aiac.ijalel.v.4n.3p.167
\end{abstract}

The research is financed by Islamic Azad University, Eyvan-e-Gharb Branch.

\begin{abstract}
The aim of this study was to examine the phonological errors made by dyslexics and non-dyslexic children in Persian orthography which is transcribed with two distinct spelling: words spelled with long vowels (transparent) and words spelled with short vowels (diacritics) are called opaque words. The sample of the study consisted of Fifteen dyslexic students with the mean age of $9.6,(\mathrm{SD}=1.5)$ and fifteen unimpaired elementary students with the mean age of $9.6(\mathrm{SD}=$ 1.4) who were Persian residents of 6th district of Tehran. All the participants were controlled for IQ, social class and behavioral disorders. The instrument used in this research was a set of phonological awareness task (rhymed word detection, rhymed word production, first sound detection, final sound detection, blending syllables and syllable deletion). Participants were required to do each of these phonological awareness tasks in order to compare their error rates in transparent and opaque words. The performance of the two groups was examined according to the effect of transparency variable. Data analysis was done using SPSS software. Overall, the finding showed that dyslexic children encountered more problems in both transparent and opaque words than did unimpaired children and the difference was statistically significant $(\mathrm{P}<0 / 05)$. On the other hand, correlation analysis (Pearson) showed a significant negative interaction between two variables (transparency and subjects) $(\mathrm{P}<0 / 001)$. This means that dyslexic children in compare to normal ones committed more errors in phonological awareness tasks. The results of this research show that the degree of the transparency of writing systems affects the phonological processing ability of individuals.
\end{abstract}

Keywords: dyslexia, phonological awareness, transparency, opaque orthography

\section{Introduction}

Children with Developmental dyslexia usually fail to acquire age-appropriate reading skills in the absence of other cognitive dysfunctions, such as poor vision, or frank neurological deficit (Stanovich, 1988b; Vellutino, 1979). Dyslexic children usually show difficulties in recognizing printed words, and perform poorly on such tasks as nonsense word reading, phonological awareness tasks, spelling, and reading comprehension (Lyon, 1995; Rack, Snowling, \& Olson, 1992). It is believed that dyslexia is an impairment which is specific to reading; however, there are abundant evidences which link dyslexia to other aspects of language, memory and perception (Adams, 1990).

An important view of dyslexia is that it is a deficit in the representation and use of phonological information (Liberman \& Shankweiler, 1985; Wagner \& Torgesen, 1987). It is believed that phonological deficits interfere with learning the correspondence between sound and spelling which is an important step in learning to read. The field of dyslexia research is dominated by the phonological deficit explanation which Stanovich (1994) summarized quite succinctly: "Most cases of reading disability arise because of difficulties in the process of word recognition. These difficulties are, in turn, due to deficiencies in processes of phonological coding whereby letter patterns are transformed into phonological codes. The precursor to the phonological coding difficulty appears to be a deficit in segmental language skills sometimes termed phonological awareness or phonological sensitivity” (p. 585).

There are many researches which provide evidence in support of phonological awareness deficits in dyslexic children (Goswami, 2000). The term phonological awareness includes several phonological segments (syllable, onset-rime, and phoneme) and several manipulations. The phoneme level is of great importance in order to understand the alphabetic principle (see Snowling, 2000). However, in order to read an alphabetic orthography, the children have to establish a system of mappings between the letter strings of printed words and the phonemic sequences that comprise spoken words. Therefore, obtaining the capacity to bring the phonemes to consciousness is a crucial step in learning to read. Researchers point to a strong link between reading difficulties and deficits in phonological skills. In order to explain the 
reading difficulties of dyslexic children, researchers put forward a hypothesis that these children come to the task of learning to read with poorly specified phonological representations ( Ehri et al., 2000; Gombert, 1992).

It is generally agreed that languages are different with regard to their orthographic transparency. In other words, languages can be placed on a continuum from transparent to opaque ones. The regularity of orthographic transparency and phonological representations can affect both the degree and the nature of reading difficulties (Caravolas \& Bruck, 1993, Wimmer, 1993). A language with a transparent orthography is a language in which there is a one-to-one correspondence between phonemes and graphemes. This means that in such orthography the number of phonemes and graphemes are exactly the same (Spencer, 2000: 155). Such orthographies are very efficient, since they do not make heavy demands on memory and they require a much more limited activation of brain regions, making them more accessible to dyslexic children. However, opaque orthographies are more memory dependent and require greater activation of the brain and this may prevent dyslexic children from achieving reading fluency. Therefore, one would expect that developmental dyslexics due to their difficulties in phonological processing show greater difficulty in processing opaque orthographies. Opaque words may be harder to process in phonological awareness task than transparent words because of difficulties in grapheme-to- phoneme conversions. (Baddeley, 1990; Just \& Carpenter, 1992).Therefore, if orthographic transparency affects the phonological processing abilities of dyslexic children, transparent words in Persian would be better recalled than opaque ones in a phonological awareness task.

Regarding the effect of orthographic transparency on reading abilities, there are different researches. For example landerl \& Wimmer (2000) believed that German dyslexic children are successful in reading and this is due to the transparent nature of German orthography and the use of phonic method to teach reading and spelling. They believed that German dyslexic children can resolve their phonological awareness difficulties by using a systemic phonemic method. Cross language comparisons have shown that children reading transparent orthographies such as Greek (Porpodas, Pantelis \& Hantziou, 1990) and Italian (Cossu, Gugliotta \& Marshall, 1995) performed more accurately in reading words and non-words compared to children reading in English (Frith, Wimmer \& Landerl, 1998). Baluch \& Danaye-Tousi (2006) compared three groups of Persian readers, namely developmental dyslexics, a group of unimpaired readers matched on age and reading age with dyslexic children. They performed a short term memory verbal test which consisted of transparent and opaque words. The results of their study showed that transparent words as a whole were read more accurately than opaque words. Jamali Nesari and Kamari (2014) compared word reading performance of Persian speaking dyslexic children through the use of a reading test. They compared 15 Persian elementary developmental dyslexic students with the mean age of 9.6 and 15 Persian unimpaired elementary student with the mean age of 9.6. The performance of the two groups was examined according to the effect of transparency variable. Participants were required to read a list of 32 one syllabic word and non-words in order to compare the reaction times and error rates of reading transparent and opaque words and non-words. Overall, the finding of their study showed that dyslexic children encountered more problems in reading both transparent and opaque words than did unimpaired children. The finding also showed that reading the opaque words was harder than reading the transparent words for both groups.

Most of the studies comparing the development of literacy in different orthographies have been concerned with reading development. However, the present study focuses on the effects of mixed orthography of Persian on the phonological awareness of dyslexic and non-dyslexic children in order to find out the similarities and differences between the two groups' errors and to draw conclusions about the nature of problems.

1- How does the phonological awareness of dyslexic children differ from that of non-dyslexic children?

In line with the findings of the previous studies, it was hypothesized that dyslexic children perform weaker that nondyslexic children.

2- Are there any statistically significant differences between the error rates of transparent and opaque words?

It was hypothesized that both groups committed more errors on opaque words than transparent ones.

\section{Method}

\subsection{Participants}

Each subject undertook six subtests of a phonological awareness task. The words were selected according to the following criteria: (1) all the words were frequent words; (2) all the words were concrete and (3) they were divided into two categories based on their transparency. The stimuli were presented to participants using DELL monitors operating at $1366 \times 768$ resolutions, with a refresh frequency of $100 \mathrm{~Hz}$. The dimensions were $47 \mathrm{~cm}$ horizontal and $30 \mathrm{~cm}$ vertical. The viewing distance was $60 \mathrm{~cm}$. The computers were DELL (2.4GHz processor, 4GBRAM, 320Gb disk drive). The experiment was designed using Open Sesame (Psychology Software Tools). In the first subtest (rhymed word detection), there were two groups of words: the first group consisted of four transparent monosyllabic rhymed word pairs and four transparent monosyllabic non-rhymed word pairs. The second group consisted of four opaque monosyllabic rhymed word pairs and four opaque monosyllabic non- rhymed word pairs. The participants had to identify the non-rhymed words in each group. In the second subtest (rhymed word production), there were also two groups of transparent and opaque words; each group consisted of four list which included three words (transparent and opaque respectively). In this subtest, children had to make up rhymes for individual words. The third and fourth subtests (initial and final sound detection), each included four transparent mono-syllabic words and four opaque mono-syllabic words. Participants had to identify the first and final sound by pronouncing the first and final sounds in each word. In the fifth and sixth subtests (blending syllables, syllable deletion), four transparent and four opaque disyllabic words 
were selected. In the in the fifth subtest, participants had to blend syllables together to make up a word and in the last subtest, participants had to pronounce the remaining part of words without either the first or the second syllable.

\subsection{Material}

Each subject undertook six subtests of a phonological awareness task. The words were selected according to the following criteria: (1) all the words were frequent words; (2) all the words were concrete and (3) they were divided into two categories based on their transparency. The stimuli were presented to participants using DELL monitors operating at $1366 \times 768$ resolutions, with a refresh frequency of $100 \mathrm{~Hz}$. The dimensions were $47 \mathrm{~cm}$ horizontal and $30 \mathrm{~cm}$ vertical. The viewing distance was $60 \mathrm{~cm}$. The computers were DELL (2.4GHz processor, 4GBRAM, $320 \mathrm{~Gb}$ disk drive). The experiment was designed using Open Sesame (Psychology Software Tools). In the first subtest (rhymed word detection), there were two groups of words: the first group consisted of four transparent monosyllabic rhymed word pairs and four transparent monosyllabic non-rhymed word pairs. The second group consisted of four opaque monosyllabic rhymed word pairs and four opaque monosyllabic non- rhymed word pairs. The participants had to identify the non-rhymed words in each group. In the second subtest (rhymed word production), there were also two groups of transparent and opaque words; each group consisted of four list which included three words (transparent and opaque respectively). In this subtest, children had to make up rhymes for individual words. The third and fourth subtests (initial and final sound detection), each included four transparent mono-syllabic words and four opaque mono-syllabic words. Participants had to identify the first and final sound by pronouncing the first and final sounds in each word. In the fifth and sixth subtests (blending syllables, syllable deletion), four transparent and four opaque disyllabic words were selected. In the in the fifth subtest, participants had to blend syllables together to make up a word and in the last subtest, participants had to pronounce the remaining part of words without either the first or the second syllable.

\subsection{Procedures}

Each subject undertook six subtests of the phonological awareness task. The participants were tested individually in a sound proof lab. All the participants received oral instructions which were recited before they started the test. Each subtest started with two trial question training sessions which were performed with completely different words than those in the real subtests. Participants were placed in front of a Dell computer at a viewing distance of $60 \mathrm{~cm}$. They were requested to perform all the six subtests of phonological awareness task. The subtests were administered in a random order. The rhymed word detection subtests started when a fixed point appeared on the screen for $500 \mathrm{~ms}$. Then the rhymed or non-rhymed word pairs appeared on the screen and after $240 \mathrm{~ms}$ the second fixation point appeared. The response time was also set to $250 \mathrm{~ms}$. The participants were required to decide whether word pairs rhymed or not and they moved to the next trial as soon as they responded to the stimuli. However, if they failed to respond within $2500 \mathrm{~ms}$, the trial disappeared and they were moved on to the next trial.

In the rhymed word production subtests the experimenter read one word in each list and the participants had to generate the next rhyming words which were presented in the same list. In the initial and final sound detection subtests, participants had to pronounce the initial and final sound of a word which the experimenter recited to him/her. In rhymed word detection subtest, the experimenter recited the first syllable of the word and after a short pause the second syllable was recited. The participants had to blend the two syllables to generate a word. In the final subtest, the experimenter recited two transparent and two opaque words and asked the participants to pronounce the remaining part of the words without the first syllable. In the next four words (two transparent words and two opaque ones), participants had to pronounce the remaining part of the words without the second syllable. The independent variables in all of these subtests were transparency (transparency versus opaqueness) and subject (dyslexic and non-dyslexic). Except rhymed production subtest in which the dependent variable was the number of correct produced rhymed words, in all the other subtests, the phonological error was taken as dependent variable. Phonological errors included wrong detection of rhymed words, wrong production of rhymed words, wrong detection of initial and final sounds, and wrong blending of existing syllables.

For the statistical evaluation of our data, independent samples t- test were performed on the number of errors made by dyslexics and non-dyslexics on both transparent and opaque words in order to detect possible statistically significant $(\mathrm{P}<0 / 05)$ differences between the two groups (dyslexic and non-dyslexic participants) and between the two different types of words (transparent and opaque words). The analysis was done with the SPSS statistical program.

\section{Results}

In this section the results of the six subtests of phonological awareness task is presented. Dyslexic and non-dyslexic children are compared. Independent samples t-test was performed and mean and standard deviation of groups were compared to give a reliable source for the data analysis and interpretation. The means and standard deviations of errors for dyslexic and non-dyslexic subjects in the first five subtests are presented in table 1 and the means and standard deviations of errors for dyslexic and non-dyslexic subjects in the last subtest (rhymed word production) is presented in table 2 . 
Table 1. The mean and standard deviations of error rates for dyslexic and non-dyslexic subjects

in the first five subtests

\begin{tabular}{|c|c|c|c|c|}
\hline Subtest/subject & $\begin{array}{c}\text { Transparent } \\
\text { words } \\
\text { (Mean) }\end{array}$ & $\begin{array}{c}\text { Transparent word } \\
\text { (std.deviation) }\end{array}$ & $\begin{array}{l}\text { Opaque } \\
\text { (Mean) }\end{array}$ & $\begin{array}{c}\text { Opaque } \\
\text { (Std.deviation) }\end{array}$ \\
\hline $\begin{array}{l}\text { Rhymed word } \\
\text { detection/ } \\
\text { dyslexic }\end{array}$ & $2 / 65$ & $1 / 32$ & $5 / 54$ & $1 / 54$ \\
\hline $\begin{array}{l}\text { Rhymed word } \\
\text { detection/ non- } \\
\text { dyslexic }\end{array}$ & $0 / 60$ & $0 / 58$ & $1 / 55$ & $1 / 12$ \\
\hline $\begin{array}{l}\text { Initial sound } \\
\text { detection/dysle } \\
\text { xic }\end{array}$ & $1 / / 37$ & $0 / 71$ & $1 / 76$ & $0 / 94$ \\
\hline $\begin{array}{l}\text { Initial sound } \\
\text { detection/ non- } \\
\text { dyslexic }\end{array}$ & $0 / 17$ & $0 / 37$ & $0 / 51$ & $0 / 54$ \\
\hline $\begin{array}{l}\text { Final sound } \\
\text { detection/dysle } \\
\text { xic }\end{array}$ & $0 / 10$ & $0 / 31$ & $0 / 15$ & $0 / 43$ \\
\hline $\begin{array}{l}\text { Final sound } \\
\text { detection/ non- } \\
\text { dyslexic }\end{array}$ & $0 / 00$ & $0 / 00$ & $0 / 05$ & $0 / 41$ \\
\hline $\begin{array}{l}\text { Blending } \\
\text { syllables/ } \\
\text { dyslexic }\end{array}$ & $0 / 35$ & $0 / 46$ & $0 / 47$ & $0 / 67$ \\
\hline $\begin{array}{l}\text { Blending } \\
\text { syllables/ non- } \\
\text { dyslexic }\end{array}$ & $0 / 00$ & $0 / 00$ & $0 / 00$ & $0 / 00$ \\
\hline $\begin{array}{l}\text { Syllable } \\
\text { deletion/ } \\
\text { dyslexic }\end{array}$ & $2 / 5$ & $1 / 95$ & $2 / 80$ & $1 / 54$ \\
\hline $\begin{array}{l}\text { Syllable } \\
\text { deletion/ non- } \\
\text { dyslexic }\end{array}$ & $0 / 30$ & $0 / 73$ & $0 / 85$ & $0 / 74$ \\
\hline
\end{tabular}

Table 2. the mean and std. deviation of rhymed word production scores in dyslexic and non-dyslexic children (in percent)

\begin{tabular}{lllll}
\hline Subtest/subject & $\begin{array}{l}\text { Transparent } \\
\text { words(mean) }\end{array}$ & $\begin{array}{l}\text { Transparent } \\
\text { words(std. deviation) }\end{array}$ & Opaque (mean) & Opaque (mean) \\
\hline $\begin{array}{l}\text { Rhymed word } \\
\text { production / dyslexic }\end{array}$ & $1 / 05$ & $0 / 65$ & $0 / 73$ & $0 / 53$ \\
$\begin{array}{l}\text { Rhymed word } \\
\text { production/ non- }\end{array}$ & $2 / 63$ & $0 / 65$ & $3 / 06$ & $0 / 90$ \\
dyslexic & & & & \\
\hline
\end{tabular}

As the results in table 1 shows, dyslexic children performed better in detection of rhymed transparent words than did in detection of rhymed opaque ones. Statistically significant $(0 / 05)$ differences were found in the error rates of dyslexic children in detection of rhymed transparent words and rhymed opaque words $(\mathrm{t}=4 / 12, \mathrm{df}=9, \mathrm{p}<0 / 008)$. As the results in table 2 shows they also produced more transparent words $(1 / 05 \%)$ than opaque ones $(0 / 73 \%)$. T-test showed a statistically significant difference in their scores on the production of these two types of words $(\mathrm{t}=3 / 234, \mathrm{df}=9, \mathrm{p}<$ 0/018).

Dyslexic children committed more errors in detection the initial sound of opaque words (1/76\%) than in detection of the initial sound of transparent words $(1 / 37 \%)$. However, the results obtained from t-test sample showed no statistically significant difference in the error rates of this children in detection of initial sound in transparent and opaque rhymed words $(t=0 / 432, d f=9,, p>0 / 32)$. Likewise, the same analysis confirmed no statistically significant differences in the error rates of them in detection of final sound in transparent and opaque rhymed words $(t=0 / 853, d f=9,, p>0 / 021)$.

The same results showed that dyslexic children committed more errors in syllable blending of opaque words $(0 / 47 \%)$ than in syllable blending of transparent words $(0 / 35 \%)$. Statistically significant differences $(0 / 05)$ were found in the error rates of dyslexic children in syllable blending of opaque words than in syllable blending of transparent words 
$(t=3 / 265, d f=9, p<0 / 05)$. The performance of dyslexic children on deletion of syllables in transparent words $(2 / 50 \%)$ was better than their performance on deletion of syllables in opaque words $(2 / 80 \%)$. However, the results obtained from $t$-test confirmed these differences not to be statistically significant ( $t=3 / 674, d f=9, p<0 / 12$ ).

Non-dyslexic children performed better in detection of rhymed transparent words than did in detection of rhymed opaque ones. Statistically significant (0/05) differences were found in the error rates of dyslexic children in detection of rhymed transparent words and rhymed opaque words $(\mathrm{t}=3 / 92, \mathrm{df}=19, \mathrm{p}<0 / 008)$. They also produced more transparent rhymed words $(2 / 63 \%)$ than opaque rhymed ones $(3 / 06 \%)$. T-test showed a statistically significant difference in their scores on the production of these two types of words $(t=3 / 17, d f=19, p<0 / 003)$.

Non-Dyslexic children committed more errors in detection the initial sound of opaque words $(0 / 51 \%)$ than in detection of the initial sound of transparent words $(0 / 17 \%)$. The results obtained from the t-test sample showed no statistically significant difference in the error rates of this children in detection of initial sound in transparent and opaque rhymed words $(t=1 / 76, d f=19,, p>0 / 41)$. Likewise, the same analysis confirmed no statistically significant differences in the error rates of non-dyslexic children in detection of final sound in transparent and opaque rhymed words $(\mathrm{t}=3 / 21, \mathrm{df}=$ $19,, \mathrm{p}>0 / 41)$.

The same results showed that non-dyslexic children committed no errors in syllable blending of opaque and transparent words $(0 / 0 \%)$. Likewise, the performance of dyslexic children on deletion of syllables in transparent words was better than their performance on deletion of syllables in opaque words. They committed more errors in syllable deletion in opaque words $(0 / 85 \%)$ than in transparent ones $(0 / 30 \%)$. The results obtained from t-test samples confirmed a statistically significant $(t=2 / 54, d f=19, p<0 / 003)$.

A comprehensive look at the data shows that there was no significant and homogenous effect of transparency on the performance of subjects in all the subtests of the phonological awareness task. This variable affected the performance of non-dyslexic subjects in four subtests (rhymed word detection, rhymed word production, blending syllables and deleting syllables). However, the same variable affected the performance of dyslexic children in only two subtests namely rhymed word detection and rhymed word production. The results obtained from the t-test samples showed that in rhymed word detection subtest, there was a statistically significant difference $(\mathrm{p}<0 / 05)$ in the error rates of both groups in the detection of transparent and opaque words $(\mathrm{t}=5 / 957, \mathrm{df}=28, \mathrm{p}<0 / 002)$. In other words, both groups of subjects had a better performance in the detection of transparent rhymed words than in the detection of opaque rhymed ones. Likewise, there was a statistically significant difference $(\mathrm{p}<0.05)$ in the production of rhymed words in both groups of subjects $(t=4 / 265, d f=28, p<0 / 001)$. In other words, orthographic transparency affected the performance of both dyslexic and non-dyslexic children in rhymed word detection subtest. However, these two groups performed differently in the production of transparent and opaque words. This means that, non-dyslexic children produced more opaque rhymed words while, dyslexic children produced more transparent rhymed words.

The effect of the second variable (subject type namely, dyslexic and non-dyslexic) was not the same in all the subtests. In the rhymed word detection subtest, there was not a statistically significant difference $(0 / 05)$ between dyslexic and non-dyslexic subjects $(t=4 / 753, d f=28, p<0 / 612)$. However, there was a statistically significant difference between dyslexic and non-dyslexic subjects in the production of rhymed words $(t=3 / 864, d f=28, p<0 / 002)$. The same results showed that there was a statistically significant difference $(0 / 05)$ between two groups in initial detection of sound ( $t=$ $1 / 604, \mathrm{df}=28, \mathrm{p}<0 / 003$ ). In other words, non-dyslexic children committed less errors in detection of initial sounds in words than did their dyslexic counterparts. Likewise, there was a statistically significant difference $(0 / 05)$ between two groups in detection of final sound $(\mathrm{t}=2 / 974, \mathrm{df}=28, \mathrm{p}<0 / 04)$ which means that non-dyslexic subjects committed less errors on this subtests than did their dyslexic counterparts. In syllable blending subtest, there was a statistically significant difference $(0 / 05)$ between two groups of participants $(t=1 / 876, d f=28, p<0 / 032)$. These results showed that dyslexic subjects in compare to non-dyslexic ones had more errors in generating words from the presented syllables. However, the same results showed that there was not a statistically significant difference $(0 / 05)$ between two groups of participants in deletion of syllables $(\mathrm{t}=4 / 321, \mathrm{df}=28, \mathrm{p}<0 / 242)$.

As an initial investigation of the relationship among transparency and subject type variables, Pearson Correlations were performed for all subtests. Except in rhymed word production subtest, there was no statistically significant correlation between transparency and subject types. In other words, only in this task, the transparency and subject type variables were related. This means that only in the mentioned subtest, non-dyslexic subjects generated more opaque rhymed words and dyslexic children generated more transparent rhymed words $(t=0 / 81, n=30, p<0 / 003)$.

The results obtained from Pearson Correlational analysis showed that there was no statistically significant $(0 / 05)$ correlation between two variables (transparency and subject type) $(\mathrm{r}=0 / 68, \mathrm{n}=30, \mathrm{p}<0 / 36)$. These results showed that in line with the transparency of words, two groups had a coordinate performance. In other words, both groups had more errors in detection of opaque rhymed words than in detection of transparent rhymed words.

The results also showed that there was no statistically significant correlation $(0 / 05)$ between two variables in initial sound detection $(r=0 / 59, n=30, p<0 / 69)$ and in final sound detection $(r=0 / 47, n=30, p<0 / 92)$. This means that both groups performed better in detection of the initial and final sounds of transparent words than opaque words. The results obtained from Pearson Correlational analysis also showed that there was not a statistically significant correlation $(0 / 05)$ between two variables in syllable blending subtest $(r=0 / 74, n=30, p<0 / 6)$. This means that, both groups had a better performance in blending syllables of transparent words than in blending syllables of opaque words. Likewise, in syllable deletion, there was no statistically significant $(0 / 05)$ correlation between two variables $(r=0 / 37, n=30, p<0.65)$. 
This means that both groups performed better in deletion of syllables in transparent words than in opaque ones.

\section{Discussion \& Conclusion}

The aims of this research were to investigate the phonological errors made by dyslexic and non-dyslexic children who were reading the mixed orthography of Persian. In other words, this research investigated the impact of spelling transparency of Persian on performance of dyslexic and non-dyslexic children in phonological awareness tasks. The fact that Persian words are written with two distinct spellings enabled the within language comparison of the error rates of words with transparent and opaque spellings. Two hypotheses were explored. First, in relation to the phonological awareness tasks, it was hypothesized that dyslexic children perform weaker than non-dyslexic children. The phonological errors of dyslexic children were more than that of non-dyslexic children. This hypothesis was based on the previously reported studies on unimpaired and impaired readers (Danaye-Tousi, 2006; Jamali Nesari \& Kamari, 2014). Moreover, with regard to developmental dyslexics, it is believed that they have greater difficulty than non-dyslexic children in retrieving phonological information ( Ehri et al., 2000; Gombert, 1992).

The second hypothesis explored was the effect of spelling transparency on phonological awareness abilities of participants. The results showed that this variable affected the performance of non-dyslexic subjects in four subtests (rhymed word detection, rhymed word production, blending syllables and deleting syllables). However, the same variable affected the performance of dyslexic children in only two subtests namely rhymed word detection and rhymed word production. This hypothesis was based on the evidence from previously reported studies on dyslexic and nondyslexic children across different orthographies which are different in the degree of transparency (Caravolas \& Bruck, 1993, Wimmer, 1993; Porpodas, Pantelis \& Hantziou, 1990) and in relation to Persian orthography which suggest that spelling transparency affects the reading performance of children (Baluch, 1992).

It was predicted that transparent words are very efficient, since they do not make heavy demands on memory and they require a much more limited activation of brain regions, making them more accessible to dyslexic children. However, opaque orthographies are more memory dependent and require greater activation of the brain and this may prevent dyslexic children from achieving reading fluency. Therefore, one would expect that developmental dyslexics due to their difficulties in phonological processing show greater difficulty in processing opaque orthographies. Opaque words may be harder to process in phonological awareness task than transparent words because of difficulties in grapheme-tophoneme conversions. (Baddeley, 1990; Just \& Carpenter, 1992). Therefore, if orthographic transparency affects the phonological processing abilities of dyslexic children, transparent words in Persian would be better recalled than opaque ones in a phonological awareness task.

The results of this research showed that reading opaque words was harder and were more prone to errors as compared to transparent words. Such within-language comparison of Persian with regard to opaqueness and transparency showed that when words lack sufficient phonological information, it has an impact on the efficient retrieving of phonological information. Similar results can be referred to across different writing systems with transparent orthographies being read with fewer errors and faster than opaque orthographies (Caravolas \& Bruck, 1993, Wimmer, 1993; Porpodas, Pantelis \& Hantziou, 1990, landerl \& Wimmer, 2000; Cossu, Gugliotta \& Marshall, 1995).

However, with regard to the number of errors, dyslexic children showed an even worse performance on error made compared to non-dyslexic children. The magnitude of differences in performance on phonological tasks between dyslexic and non-dyslexic children in Persian can be related to the opaque aspects of Persian spelling. The finding that developmental dyslexic children in this study showed greater difficulties in phonological awareness tasks than nondyslexic children can be an indication of specific impairment in phonological processing. According to (Baluch \& Danaye-Tousi, 2006) "an immediate implication that results from these results is that there should be continuous reading instruction with words spelled with their diacritic(s) until readers have gained greater phonological skills and established a more substantial orthographic lexicon. The current teaching practice in Iran includes the use of textbooks in which words appear in text without diacritics after only two years of reading instruction".

In summary, it may be argued that dyslexic children in compare to dyslexic ones perform weaker since they have difficulty in retrieving the phonological information of the words. However, the opaqueness of a words spelling can be a contributing factor that is more taxing to memory in early stages of reading.

\section{References}

Adams, M. (1990). Beginning to read. Cambridge, MA: MIT Press.

Baluch, B., \& Danaye-Tousi, M. (2006). Memory for words as a function of spelling transparency. The Journal of Psychology, 140 (2), 95-104.

Bradley, L., \& Bryant, P. (1983). Categorizing sounds and learning to read - A causal connection. Nature, 301, 419-421. Babbeley, A. D. (1990). Human memory: Theory and practice. Hillsdale, NJ: Lawrence Erlbaum Associates.

Baluch, A. D. (1992). Reading with and without vowels: What are the psychological consequences? Journal of Social and Evolutionary System.

Caravolas, M., \& Bruck, M. (1993). The effect of oral and written language input on children'sphonological awareness: A cross-linguistic study. Journal of Experimental Child Psychology, 55, 1-30. 
Cossu, G., Gugliotta, M., \& Marshall, J. C. (1995). Acquisition of reading and written spelling in a transparent orthography: Two non-parallel processes? Reading and Writing, 7, 9-22.

Ehri, L. (2000). Learning to read and learning to spell: Two sides of a coin. Topics in Language Disorders, 20(3), 19-49.

Frith, U., Wimmer, H., \& Landerl, K. (1998). Differences in phonological recoding in German- and English-speaking children. Scientific Studies of Reading, 2, 31-45.

Goswami. U. (2000). Phonological representations, reading development and dyslexia: towards a cross-linguistic theoretical framework. Multilingualism and Dyslexia. 6 (2). 133-151.

Jamali Nesari, Sh., \& Kamari. E. (2004). Dyslexic children and their difficulties in reading Persian orthography. Advanceds in Language and Literary Studies. 4, 17-21.

Just, M. A., \& Carpenter, P. A. (1992). A capacity theory of comprehension: Individual differences in working memory. Psychological Review, 99, 122-149.

Liberman, I., \& Shankweiler, D. (1985). Phonology and the problems of learning to read and write. Remedial and Speech Education, 6, 8-17.

Lyon, G. R. (1995). Toward a definition of dyslexia. Annals of Dyslexia, 45, 3-27.

Poepodas, C. D., Pantelis, S. N., \& Hantziou, E. (1990). Phonological and lexical encoding processes in beginning readers: Effects of age and word characteristics. Reading and Writing, 2, 197-208.

Rack, J. P., Snowling, M. J., \& Olson, R. K. (1992). The non-word reading deficit in developmental dyslexia: A review. Reading Research Quarterly, 27 (1), 28-53.

Snowling, M. J. (2000). Dyslexia (2nd ed) Oxford: Blackwell.

Snowling, M. (1987). Dyslexia: A cognitive developmental review. Oxford: Blackwell.

Spencer, K. (2000). Is English a dyslexic language? Dyslexia, 6, 152-162.

Stanovich, K. E. (1994). Does dyslexia exist? Journal of Child Psychology and Psychiatry, 35, 579-595. Stanovich, K. E. (1988). The right and wrong places to look for the cognitive locus of reading disability. Annals of Dyslexia, 38, 154177.

Vellutino, F. R. (1979). Dyslexia: Theory and research. Cambridge, MA: MIT Press.

Wimmer, H. (1993). Characteristics of developmental dyslexia in a regular writing system. Applied Psycholinguistics, 14, 1-33. 